IMHOF, P., HEDINGER, F. \& KASER, H. (I962). Über Kreislaufstörungen und Veränderungen 3-Methoxy-4-Hydroxymandelsäure-Ausscheidung im Urin nach traumatischen Läsionen des Rückenmarks. Helv. Med. Act., 29.

MAURY, M. (1962). Des manifestations neuro-végétatives dans les lésions médullaires. Presse méd., 74, I673.

Paeslack, V. (1965). Internistische Störungen beim Paraplegiker. Stuttgart: G. Thieme.

\title{
CARDIOVASCULAR REFLEXES IN TETRAPLEGIA
}

\author{
By J. L. Corbett, H. L. Frankel and P. J. Harris \\ National Spinal Injuries Centre, Stoke Mandeville Hospital
}

\section{INTRODUCTION}

PREvious reports have concluded that cardiovascular control mechanisms in tetraplegics are defective due to disruption of the spinal pathways linking supra-spinal control centres with the peripheral sympathetic outflow (e.g. Bors \& French, I952; Kurnick, I956; Guttmann, Munro, Robinson \& Walsh, 1963). There have been few investigations of how this influences the stability of the cardiovascular system in tetraplegics in their day-to-day life or of what control mechanisms exist to permit the degree of rehabilitation which is possible. This is partly because the effects of the various stimuli, which may affect cardiovascular stability and which the tetraplegic may encounter, have not been specifically investigated. There are also confusing and conflicting results in previously published reports due to poor experimental design. Patients with incomplete cord transections have not been differentiated from patients with complete transections; patients with acute cord transections have not been differentiated from those with chronic transections; patients with lesions at various levels have been grouped together and in several instances not enough information has been provided to enable the reader to determine precisely the status of the nervous systems of the patients who have been investigated.

The experiments described in this paper were designed to investigate cardiovascular instability, particularly alterations in blood pressure which occurred in seven tetraplegic patients in response to some stimuli which they normally encountered in their day-to-day life and which might be expected to have a hypertensive or hypotensive effect. The first, bladder percussion, is used to stimulate bladder emptying in tetraplegic patients who are not catheterised and who have automatic bladders (Head \& Riddoch, I9I 7). The second, skeletal muscle spasms, commonly occur since they are the result of transection of spinal somatic pathways (Head \& Riddoch, 1917; Riddoch \& Head, 1917). Thirdly, tolerance of the upright posture is necessary for rehabilitation to wheel-chair life. Further results and responses to other stimuli are reported elsewhere (Corbett, Frankel \& Harris, I971, $a, b$, and $c$ ).

\section{METHODS}

The observations were made on seven subjects, each of whom had a clinically complete chronic cervical cord transection at a level between $\mathrm{C}_{5}$ and $\mathrm{C}_{7}$. Six of the subjects normally spent their day out of bed in a wheel-chair and at the 
time of the experiments none of the subjects was taking any medication nor was any suffering from any constitutional illness which may have affected the results. All subjects had volunteered after having the nature and purpose of the investigations explained fully and later ones observed the procedures on early ones before giving consent.

In each subject arterial blood pressure was measured by an electromanometer connected to a catheter inserted percutaneously into a brachial artery. The instantaneous heart rate was derived from the blood pressure trace by a beat-tobeat heart-rate meter. Measurements of peripheral blood flows were obtained from the forearm, calf and hand by intermittent venous occlusion plethysmography using a water displacement plethysmograph on the hand and a mercuryin-rubber strain gauge on the forearm and calf (Greenfield, Whitney \& Mowbray, 1963).

A saline-filled catheter connected to an electromanometer was inserted into a superficial vein of the hand and/or foot. Peripheral venous activity was studied by measuring intravenous pressure changes while the circulation of the part was temporarily isolated for periods up to ten minutes by inflating a cuff around the respective wrist or ankle to a pressure greater than arterial pressure. Any increase in intravenous pressure in the segment of isolated circulation is due to a venoconstriction (Samueloff, Bevegard \& Shepher, I966).

In three patients who had indwelling urethral catheters, bladder pressure was measured by connecting a sterile electromanometer to the catheter. All patients had automatic bladders and, in those who did not have a catheter in place, bladder emptying was induced by gently percussing the anterior abdominal wall immediately above the pubic crease until the detrusor muscle was felt to contract.

During the experiments muscle spasms varying in duration and intensity occurred in muscles innervated from below the level of the spinal cord lesion, sometimes after stimulation of the patient and sometimes without any apparent cause. The resulting movements of the patient and the disturbance to the measuring equipment made it difficult to obtain measurements during the most violent of these spasms. For more controlled observations, spasms of variable intensity were induced by scratching the sole of the foot.

To measure the effects of changes in posture on the circulation the patients were placed supine on a tilt-table which was capable of being rotated from the horizontal to a near vertical position. Each patient was subjected to a series of tilts to several different angles.

\section{RESULTS}

Bladder percussion often resulted in urination but if the bladder was empty and no urine was passed the detrusor muscle was still felt to contract. The cardiovascular response to bladder percussion did not depend on the passage of urine since it occurred whether the bladder was full or empty. Typical changes in one patient (T. G.) are shown in Figure I which illustrates the effect of three episodes of bladder percussion, two of which resulted in urination and one of which did not.

The systolic and diastolic blood pressure rose. The heart rate, calf blood flow and hand blood flow decreased with the hand blood flow falling to unrecordably low levels in some patients. These changes were always accompanied by a venoconstriction. The average increase in the mean blood pressure was 20 per cent. 
the average decrease in heart rate was Io per cent., the average fall in calf blood flow was 20 per cent., and the average fall in hand blood flow 70 per cent.

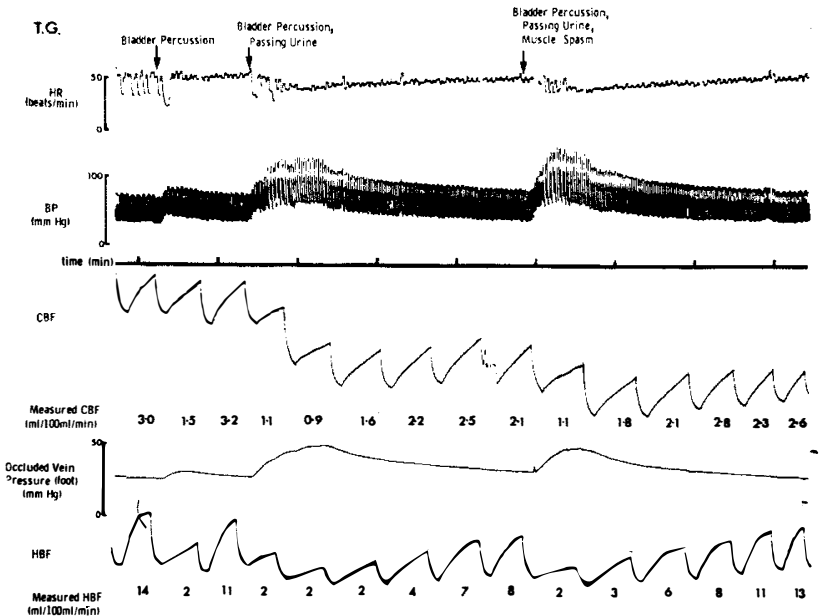

FIG. I

Typical response of heart rate (HR), blood pressure (BP), calf blood flow (CBF) pressure in an occluded vein and hand blood flow (HBF) to bladder percussion alone; bladder percussion resulting in urination and bladder percussion resulting in urination and muscle spasm.
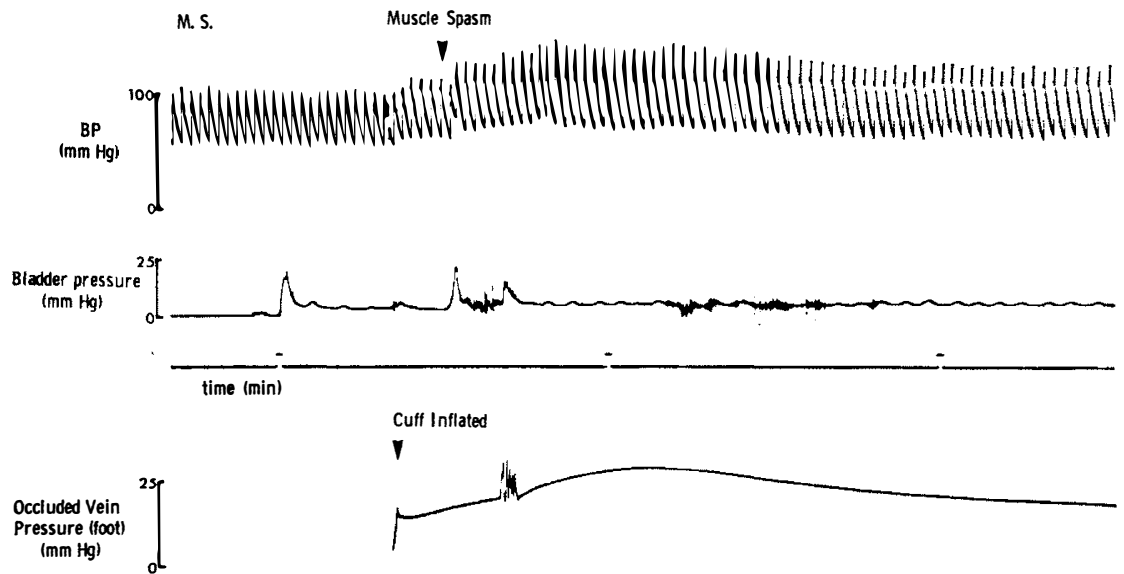

FIG. 2

Typical response of blood pressure (BP), bladder pressure and pressure in an occluded vein to a skeletal muscle spasm which was produced by sudden inflation of a cuff around the ankle of patient M. S.

The same cardiovascular changes were recorded in response to skeletal muscle spasms. The average increase in mean blood pressure was 19 per cent., the average decrease in heart rate was 5 per cent. and the average decrease in 
calf and hand blood flow was Io per cent. and 30 per cent. respectively. Figure 2 illustrates for one subject the typical response to a skeletal muscle spasm which was caused by inflating a cuff around the ankle. Although there was a rise in blood pressure and a venocontraction there was very little change in bladder pressure measured from the indwelling urethral catheter.

Head-up tilting resulted in a progressive fall in mean blood pressure accompanied by a reciprocal rise in heart rate with both measurements reaching respective minima and maxima in the third or fourth minute. When the patient was returned to the horizontal the blood pressure and heart rate returned to pre-tilt levels without any overshoot. The fall in blood pressure was usually accompanied by a

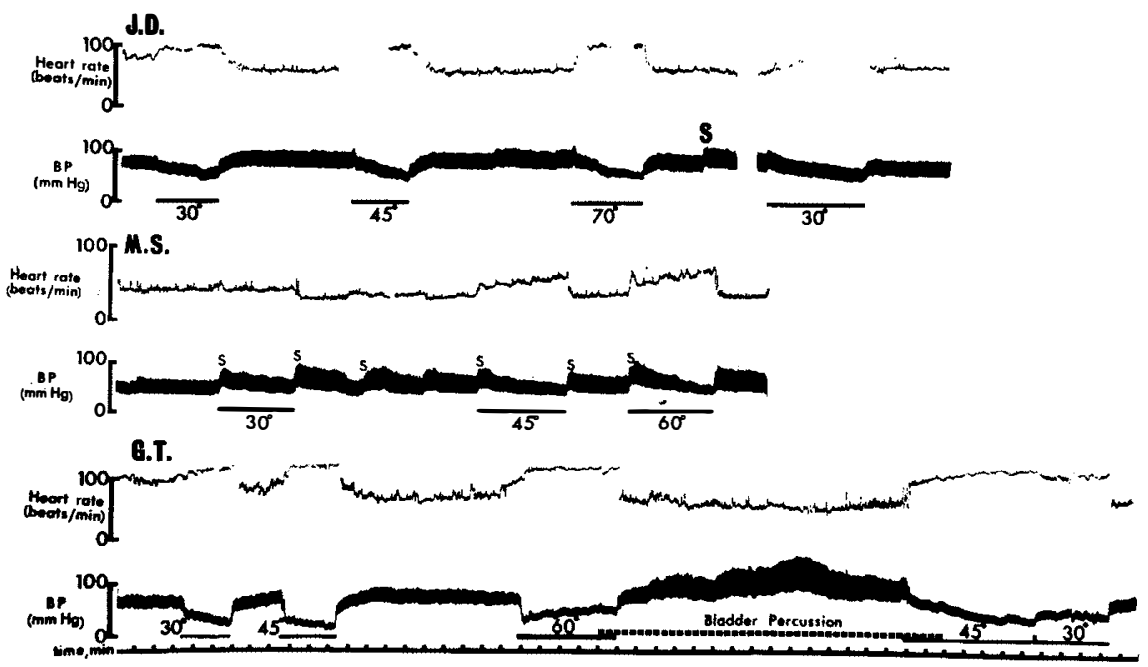

FIG. 3

Heart rate (HR) and blood pressure (BP) response to head-up tilting. The trace from patient J. D. shows the usual response and the trace from M. S. and G. T. shows the response when muscle spasms and bladder percussion, respectively, are superimposed on the postural stimulus.

decrease in forearm blood flow which on occasions reached unrecordably low levels, and by a short-lasting venoconstriction at the beginning and end of each tilt. For $45^{\circ}$ tilts the average decrease in mean blood pressure and increase in heart rate was $5 \mathrm{I}$ and 58 per cent. respectively.

The basic pattern of blood pressure and heart rate response is illustrated for patient J. D. in Figure 3. Alterations in this pattern occurred if either of the two previously described hypertensive stimuli were superimposed on the hypotensive postural stimulus. Thus the occurrence of a spasm at the beginning of a tilt tended to delay the fall in blood pressure and the occurrence of a spasm at the end of a tilt caused an overshoot in the blood pressure beyond pre-tilt levels (patient M. S. in Figure 3). Bladder percussion or spontaneous urination during a tilt also tended to oppose the fall in blood pressure (patient G. T. in Figure 3).

Overall, the range of blood pressure experienced by each patient, from the highest blood pressure during bladder percussion or muscle spasm to the lowest during tilting, varied from $60-100 \mathrm{~mm}$. $\mathrm{Hg}$. 


\section{DISCUSSION}

These experiments emphasise the need for close attention to experimental design and procedure when investigating the cardiovascular system in tetraplegic patients. Skeletal muscle spasms occur frequently, yet their cardiovascular effects have never been described, so it is possible that some cardiovascular responses previously ascribed to other stimuli have in fact been due to skeletal muscle spasms. Many features of the response to head-up tilting in tetraplegics are similar to the response to tilting in normal persons who have been subject to long periods of bed rest (Miller, Johnson \& Lamb, 1964). Again it is possible that where normally bed-ridden tetraplegics have been used in tilting experiments the observed hypertensive response has been due to the prolonged bed rest rather than to their cord lesion.

During head-up tilting the blood pressure may fall to levels which cannot be measured with a sphygmomanometer. If this is the method of blood pressure measurement used in tilting experiments on tetraplegic patients then not only is it a source of error but it constitutes a danger to the subjects since the extent of a blood pressure fall may remain unknown.

The responses to bladder percussion and skeletal muscle spasms are very similar to the response to bladder distension described by Guttmann and Whitteridge in 1947 and Cunningham, Guttmann, Whitteridge and Wyndham in I953, although these authors did not obtain direct evidence of the involvement of the venous system.

A decrease in blood flow in the presence of a rising blood pressure indicates an active resistance vessel contraction and the method used for measuring venous activity will only measure an active venoconstriction. Therefore the rise in blood pressure which occurred in response to skeletal muscle spasm and bladder percussion can be explained on the basis of a peripheral vascular constriction involving both arterial and venous segments of the peripheral circulation. A venoconstriction also occurred during head-up tilting and although the forearm blood flow decreased in the presence of a falling blood pressure, the large magnitude of the decrease in some patients may indicate that it was also partly due to an active constriction. The changes in heart rate throughout the experiments may be explained on the basis of reflex vagal activity resulting from arterial baroreceptor stimulation.

It may be concluded that in patients with complete cervical cord transection there are some cardiovascular reflexes, involving the peripheral circulation, which continue to function at a spinal level. These spinal reflexes under some circumstances may be beneficial to the patient but cardiovascular regulation is not completely normal since profound hypotension may occur during head-up tilting. The combined effect of the remaining reflexes and the defect in regulation result in considerable variation in blood pressure in response to everyday stimuli.

The question then arises as to whether attempts should be made to stabilise the cardiovascular system on tetraplegics. Detrimental effects could arise from hypertension, peripheral shutdown, vagal depression of the heart or hypotension. The first two could possibly be counteracted by the use of $\alpha$-adrenergic blockade and this would probably indirectly prevent vagal depression of the heart but, if necessary, atropine could also be used for this purpose. 
The use of pharmacological agents could eliminate the reflex hypertensive and vasoconstrictive response to stimuli such as bladder percussion, skeletal muscle spasm and bladder distension but in so doing they would also remove whatever beneficial effects these responses might have, particularly during headup tilting. A better policy would be to take a prophylactic approach and to avoid these stimuli. In the case of muscle spasms which are often spontaneous it would not matter so much since they are by nature short-lasting.

To attempt to improve the response to head-up tilting by the use of peripheral constricting agents would potentiate the response to hypertensive stimuli when the patient was horizontal. The experiments described in this paper indicate that perhaps stimulation of peripheral constriction by stimuli such as bladder tapping might provide a physiological compensation for the hypotension. These reflex responses could aid in the development of tolerance to the upright position and could also be used to overcome the acute hypotensive episode while in this position.

\section{SUMMARY}

The effects of bladder stimulation, skeletal muscle spasms and head-up tilting were observed in seven patients with complete cervical cord lesions. Measurements were made on intra-arterial blood pressure, heart rate, hand, forearm and calf blood flow and peripheral venous activity.

On bladder stimulation there was an increase in blood pressure and a decrease in heart rate, calf blood flow and hand blood flow; there was venoconstriction. Skeletal muscle spasms caused similar changes.

Head-up tilting caused a fall in blood pressure with a rise in heart rate. There was a decrease in forearm blood flow and there was some venoconstriction.

\section{RÉSUMÉ}

Les effets de la stimulation vésicale, les spasmes musculaires et la verticalisation ont été observés chez 7 malades avec une lésion cervicale complète.

Des mesures ont été faites sur la pression artérielle, intra-artérielle, le rythme cardiaque, le débit sanguin au niveau de la main, de l'avant-bras et du mollet ainsi que l'activité veineuse périphérique.

Au moment de la stimulation vésicale, il a été notés une augmentation de la pression artérielle, une dinimution de rythme cardiaque, du débit sanguin au niveau du mollet, de la main et, par ailleurs, une veno-constriction. Les spasmes musculaires ont donné des changements similaires.

La verticalisation a créé une chute de la pression artérielle, et une augmentation du rythme cardiaque. Par ailleurs, une diminution du débit sanguin au niveau de l'avantbras et une veno-constriction ont été notés.

\section{ZUSAMMENFASSUNG}

Die Effekte von Blasenstimulation, Muskelspasmen und Kippen von der horizontalen zur vertikalen Körperlage wurden an 7 Patienten mit kompletten Cervikalläsionen studiert. Intra-arterieller Blutdruck, Puls, Hand-Forarm und Bein-Blutumlauf sowie periphere venöse Aktivität wurden gemessen.

Blasenstimulation resultierte in Anstieg von Blutdruck und Verminderung des Pulses, Waden-und Handblutumlauf und Vasokonstriktion. Muskelspasmen erzengten ähnliche Veränderungen.

Augwärts-Kippen verursachte Fall im Blutdruck und Steigerung der Pulsfrequenz, ferner Verminderung des Unterarmblutumlauf und etwas Venokonstriktion. 


\section{REFERENCES}

Bors, E. \& French, J. D. (1952). A.M.A. Arch. Sur., 64, 803.

Corbett, J. L., Frankel, H. L. \& Harris, P. J. (I97I). F. Physiol., (a) 215, 38I; (b) 215, 395; (c) 215, 4I I.

Cunningham, D. J. C., Guttmann, L., Whitteridge, D. \& Wyndham, C. H. (I953). F. Physiol., 121, 581.

Greenfield, A. D. M., Whitney, R. J. \& Mowbray, J. F. (1963). Brit. Med. Bull., I9, ior. Guttmann, L., Munro, A. F., Robinson, R. \& Walsh, J. J. (1963). Paraplegia, I, 4. GutTMANN, L. \& WhitTERIDGe, D. (I947). Brain, 70, 36I.

HEAD, H. \& RidDOCH, G. (1917). Brain, 40, I88.

KuRnick, N. B. (1956). Ann. intern. Med., 44, 678.

MilleR, P. B., Johnson, R. L. \& Lamb, L. E. (I964). Aerospace Med., 35, II94.

RIDDOCH, G. \& HEAD, H. (I9I7). Brain, 40, 264.

Samueloff, S. L., BeVEgard, B. S. \& SHEPHERD, J. T. (1966). F. Appl. Physiol., 21, 34I.

\section{Discussion}

Dr. A. Rossier (Szitzerland). I was most interested in the paper of Dr. Corbett and his colleagues and their experiences on cardiovascular reflexes in tetraplegics. In fact, one patient of mine thought he was fainting and every time he was feeling poor when sitting after a while, he was just making that striking movement with his hands against his belly, repeatedly during the day. I measured the pressure and I found that the blood pressure was going up when he was doing this trick. He was just eliciting autonomic dysreflexia. Now, as far as cardiac output is concerned, which you told us not to have measured, as far as I remember Cunningham and Guttmann have measured cardiac output during these circumstances, during hypertension and autonomic dysreflexia, and they proved that there was no elevation of cardiac output.

Dr. H. TALBOT (Chairman). Two comments I would like to offer. One has to do with the demonstration of elevation of blood pressure being rather dependent upon contraction of the bladder than upon its distension. I can personally attest to having made this observation on a number of occasions when bladder contraction was induced and the bladder which was not distended by irritating substances: and this is regularly followed by an elevation of blood pressure. It is apparently distinctly the activity of the bladder muscles rather than its simple distension, although the latter may play some part in stimulating the hyper-reflexive activity of hypertension. The same can be said in terms of the rectum: on several occasions with patients in postural syncope, I have had the experience following the suggestion of Dr. Corbett not of distending the rectum but simply of massaging the anal sphincter, dilating it relatively gently, not too vigorously, and producing some restoration of blood pressure and recovery from syncope. I should like to ask Dr. Silver whether in his opinion, respecting the case in which the hyper-reflexic response seemed to appear rather precociously, whether in his opinion the speed with which the bladder is filled may possibly have an effect; again this refers to the possibility that it's the contractal activity of the bladder. The speed with which you fill the bladder will frequently stimulate contractions to occur at a much lower level of distension than would otherwise have been the case. I wonder if Dr. Silver agrees that in this case the patient was undergoing a rather active diuresis-the bladder filled rather abruptly-and whether this might possibly have had some effect on this phenomena.

Sir LUDWIG GuTTMANN $(G . B$.$) . We have heard very interesting papers indeed, and I do$ congratulate those colleagues who have done these very detailed studies. When I started these investigations on the autonomic system, in 1944, first alone and then with the help of my colleagues, we did not have these very refined methods at our disposal. Sometimes six to eight of my colleagues were standing around the patient, everyone had a certain task to carry out at an exact time-five minutes, ten minutes and so on, according to the speed of filling the bladder. That was, of course, a rather difficult task. Yet the results achieved have been confirmed throughout the world whatever techniques were used. 
I should like to make one point to Dr. Corbett. He showed in case A. T. of postural hypotension, that before that man got a fall of blood pressure, there was an increase of blood pressure just before. That was a point we noticed already in our previous publication and this is very interesting because it shows how compensatory reflexes come into action immediately in this state of emergency. I am sorry that you haven't related your studies on visceral distension with the investigations of the effect of this autonomic reflex phenomenon on the catacolamines. In my first paper with David Whitteridge in 1947 we came to the conclusion that it was a reflex response initiated by vasoconstriction in the paralysed area. But, there was one point we really didn't know: what role do the catacolamines-adrenalin and noradrenaline-play in this? I have done this study later with the help of my biochemist Mr. Robinson, and it proved that, while at the stage of hypertension following bladder distension both adrenalin and noradrenalin rise too, it is an associate reaction rather than the cause of vasoconstriction. I could not find that the increase of noradrenalin and adrenalin started before. So, we can say now, with some degree of certainty that the whole phenomenon is a widespread reflex response of autonomic mechanisms, but I think this should be re-examined.

Another point I would like to mention for further examination is the effect of change of posture in these high lesions in the early stages following cord transection. From the beginning, I found that change of posture is a very important stimulus to improve postural hypotension, the reason being that if a patient is turned from the supine to the lateral position, the blood goes down and the big vessels react to distension like the bladder, i.e. they react as a hollow organ like the bladder and the guts, with contraction due to stimulation of their intramural autonomous innervation. If you continue this turning regularly, this is, I would say, the first exercise to restore the vasomotor control in some way. I would like to suggest this for further investigation. Finally, Dr. Silver mentioned the case where he found the autonomic hyperreflexia in the acute cases. This proves the importance of the quantity of fluid to elicit the autonomic hyperreflexia in hypotonic or atonic bladder in the acute stage. He got the hyperreflexia in a stage when the bladder was extremely distended and I am a bit surprised that the distension of the bladder was only discovered after the X-ray was done. Finally, from an historical point of view, I should like to tell you that the first really exact investigation of the relation of visceral distension to blood pressure was done by Sherrington by distending the gall bladder in a cat.

ChaIRMan. There remains time for closing comments by our essayists.

Dr. CoRbett (G.B.). There are a few comments I would like to make. Firstly, I think it worth saying something about Valsalva's manoeuvre. In the past five years, I have measured over 500 or 600 of these and studied them in very great detail indeed, and I maintain very strongly that this is a subject about which there is incredible confusion. In the literature there are 28 different ways of doing Valsalva's manoeuvre. They range from a very short time up to a minute, the pressures are very variable and the conditions are very ill-specified, and Valsalva's manoeuvre as a term means nothing. The next thing I would say is that if one is to talk about the interpretation of Valsalva's manoeuvre it is very important to make measurements, and I have tried in these studies with Dr. Harris and Dr. Frankel to study Valsalva's manoeuvre in tetraplegics. I have had a number of successful studies, but I have had a very large number of unsuccessful ones, and the point is that it is extremely difficult to do this manoeuvre in a patient with tetraplegia, because most patients have spasms, and it is very difficult to maintain any sort of constant pressure in the oesophagus. Without measuring oesophageal pressure it is very difficult to know what the stimulus is; without observing spasms it is very difficult to know as well. This is not intended to be a criticism of Dr. Silver; what it is intended as is a criticism of many comments in the literature on Valsalva's manoeuvre. Really, a plea is made that, if it is going to be used, it must be interpreted very carefully indeed.

The next thing I would say is about the interpretation of forearm blood flow. I 
again make a very strong plea that forearm blood flow results must not be interpreted without a concurrent measurement of blood pressure. Because forearm blood flow is going to depend on two things: passive changes as a result of changes in the profusion pressure, and active changes as a result of constriction of vessels. If one doesn't know what the profusion pressure has done-and I think it must be measured with a catheter to be able to make these observations-one cannot say whether the changes are active or passive. There is an extreme amount of confusion in the literature, in confusing the terms 'decrease in forearm blood flow' with 'vasoconstriction'; they mean totally different things, and I think that is something which must be avoided at all costs.

The next thing which in the interpretation one must point out is that the magnitude of changes can have too much read into them. It does not mean-because the hand blood flow or the skin blood flow changes from 15 to say 5 per $100 \mathrm{ml}$. per minute and the muscle blood flow changes from 3 to $2 \cdot 5$-that the muscle blood flow changes are insignificant or less significant. The functional importance of the quantitative change has never been assessed, and it is quite possible that changes which numerically are not very large have a very large functional importance in the regulation of blood pressure in a patient. So, the use of qualitative terms as saying greater and smaller changes in one compared with the other is not justified and it can lead to a lot of misinterpretation.

The term 'autonomic hyperreflexia' has had a lot of glorious predecessors, of which the best I know is poikyelosporesis spinalis. It is one that I am a little unhappy about, because in fact what one is saying is that the efferent pathway in these reflexes is exaggerated and the afferent pathway is not playing its part, or the compensatory mechanisms are not there, and one has a combination of the presence, probably, of normal reflexes or perhaps slightly exaggerated ones, but the absence of compensation. And to talk about hyperreflexia, I think, distorts the issue slightly, because one suggests that all reflexes are over-active, and what in fact is the case is that some are absent. I have discussed with Dr. Silver before, the question of whether spasms are known to do these things, and I simply say that I do know the world literature extremely closely and I don't believe that the effect of spasms is in any way adequately documented and I don't believe that its effect on blood pressure is clearly known at all.

Dr. Rossier commented on cardiac output and drew attention to the fact that Dr. Cunningham and others had noted this a long time ago. What I would say is that particular paper cardiac output was measured with Grolman's method which is a rebreathing method dependent on acetyline. They thought, in fact, that the results were so worthless that they didn't even discuss them; they drew attention to that in that paper. They presented the methods and the results and said these results are so hopeless that we won't discuss them. Since that time, Ohlson and Hastings in I963 have also used that method and I would be prepared to dissect that paper in a rather scandalous fashion, because the results are not consistent within themselves in that paper, the method is open to very great errors indeed, particularly in a patient who has respiratory embarrassment and can't rebreathe adequately. Freshjus and Miltzen in 1969 also made measurements and I think we have there the first paper where adequate measurements of cardiac output have been made, even though the report is very scanty. And there are some conflicts also within that paper but we can't be sure. I am simply saying that cardiac output is a difficult measurement and I am really asking that in studies on these patients the methodology be very clear and that experimenters shouldn't read more into them than there really is.

I very much take Sir Ludwig's point about the importance of hormones in these states. We would like to do more and I hope that we will do more. I think that hormones are playing a part. I think that the difficult question will be to decide whether these changes are secondary to neurogenic mechanisms or whether they are secondary to ischaemia.

Dr. Silver (G.B.). Mr. Chairman, you raised the point about the question of the distension of the bladder, whether it was the speed of the distension that elicited the 
reflex or whether it was the volume. We all know that if you do a cystometrogram rapidly you get a stronger contraction, and Comarr introduced this conception of doing a natural cystometrogram by letting the urine distend the bladder slowly. Now in the case that I described this was a natural cystometrogram, it was the urine that did it, and it was up to a much higher volume. When I repeated the procedure, several days later, filling the bladder rapidly, it did not produce nearly such a marked effect, so I would entirely agree with Sir Ludwig's concept that it is the force of the stimulus doing it at a later stage. Now, with regard to the other point, the question of Valsalva's manoeuvre, I am well aware that there are about 28 different methods of producing the Valsalva manoeuvre. When I came to do this study I followed the technique that was used at St. Thomas's Hospital, where I learned the venous occlusion plethysmography of maintaining the pressure against a certain level of mercury. I did not follow the Oxford technique of blowing air down an open tracheostomy, which had been described in the Oxford Department of Physiology, where this method was discussed, and this appeared to produce acceptable results. There were many patients who could not maintain this pressure because they were not strong enough, and I took the precaution of using a wide mouthpiece, so that they were in fact blowing from their lungs and not producing trick movements from their lips. I didn't have the facilities to measure intra-arterial pressure.

The question of the spasms: this has been documented by several writers on the question, Guttmann described it in 1947. In the original paper we made the point that when spasms were recurring we discontinued the observations because we were aware that it caused a fall in the blood flow, and there were several of the slides which I couldn't show later on which illustrated the effect of spasms on the blood flow and on the blood pressure. The question of drugs: there was a very full discussion of the method of treatment, and drugs were suggested. I make the point that there has been a lot of discussion on the peripheral arterial system and on the cardiac output, but when you consider the matter, 90 or 85 per cent. of the circulating blood volume is held in the blood vessels - the veins. Any discussion of the circulatory system that does not take into account the veins is missing the point at issue. Again, in some of the slides I couldn't show how I obviated this problem. I tried to study it by tilting the legs up in the air, trapping as much blood as I could within the capacity of the veins and putting cuffs on. Then I carried out tilting procedures with the patient upright with the cuffs off and the patient very rapidly fainted. I then carried out the procedure with the cuffs on and the patient could maintain consciousness. So it seemed to me you have the two problems: the problem of the paralysis of the sympathetic, which, as Dr. Corbett has beautifully demonstrated, is not nearly so marked, and the effects of the paralysis on the cardiac return due to paralysis of the muscles, which affects the venous system as well. This has not been studied in detail. There have been some quite nice studies at Oxford of the nerve supply of the veins, and the venous tone, and, this is important, which leads me on to two more points: the question of treatment. The use of G-suits has been described in America where this procedure is used to treat the patients, while at Stoke Mandeville they put tight stockings on the legs and abdominal binders to improve venous return. I think this is much more to the point than introducing bits of equipment into the patient's rectum or into the bladder or compressing it. The suggestion that the patients with spasms do better is one that I would dispute all the way, and I don't think there is a single clinician here who would accept that any cervical patient with spasms is a happy person. They are, I think, our greatest clinical problem-these patients crippled, with their arms, hands and knees drawn up-and we are often presented with this problem of should we block out the spasms and take out the little bit of remaining movement so that they can be free of these terrible, troublesome spasms. When you question these cervical patients who have had alcohol blocks or rhizotomies to get rid of these spasms they say that they are only grateful that they can sit in a chair. 